\title{
INTRODUCTION AND ACKNOWLEDGMENTS
}

The loss of Chava Rosenfarb in early 2011 gave this issue of Canadian Jewish Studies a new urgency. We had already begun collecting papers for the issue, some of which were presented at a special session on Rosenfarb at a conference of the Association for Canadian Jewish Studies held in Montreal in 2010. Editing these papers to put Rosenfarb in the past tense was a sad experience. Immigrant, Yiddish-speaking culture can still be studied, but we are fast losing our direct connection to this past with the passing of the Holocaust refugee and survivor generation.

The investigation of Yiddish in Canada is in its infancy. This collection is an effort to bring together some of the researchers who are currently working in the field. The papers gathered here show that there is a great variety of ways to approach Yiddish in Canada: through statistical analysis, interviews, close readings of texts, archival research, and through making connections between these modes of analysis. We thank these writers for their fruitful endeavors. We are indebted to the anonymous reviewers, whose comments allowed the writers to bring their best ideas forward. Eiran Harris' compendium of Hebrew and Yiddish printed matter will, we hope, stimulate interest and further study, and we thank him for allowing us to publish it here.

We also appreciate the support and help of incoming journal editors Stephanie Tara Schwartz and David Koffman; book review editor Ira Robinson; association president Randall Schnoor; translator Chantal Fournier; graphic artist Teresa Lynne; and Zachary Baker, Richard Menkis, and Brad Sabin Hill, who offered editorial advice and assistance. The Jewish 
Public Library, in Montreal, and the Jewish Heritage Centre of Western Canada, in Winnipeg, have been consistently helpful in fact-checking and providing photographs.

Finally, we have dedicated this volume to the memory of Naomi Kadar, an inspired and inspiring New York-based teacher who, over the years, taught numerous young researchers how to make Yiddish a part of themselves. May her memory be a blessing.

Faith Jones Rebecca Margolis 